Int. J. Electrochem. Sci., 14 (2019) $3651-3662$

International Journal of

ELECTROCHEMICAL

SCIENCE

WWW.electrochemsci.org

\title{
Effect of Aging Treatment on Corrosion Resistance of S32750 Super Duplex Stainless Steel in Simulated Seawater at Low Temperature
}

\author{
Lan Jin, Ping Liang*, Yanhua Shi, Yier Guo, Yan Zhao, Fei Li, Guanyu Hou \\ School of Mechanical Engineering, Liaoning Shihua University, Fushun 113001, China \\ *E-mail: liangping770101@163.com
}

doi: 10.201964/2019.04.29

Received: 30 November 2018 / Accepted: 28 January 2019 / Published: 10 March 2019

Electrochemical corrosion behaviors of S32750 super duplex stainless steel (SDSS) with different temperature aging treatment range from $650{ }^{\circ} \mathrm{C}$ to $850{ }^{\circ} \mathrm{C}$ in the simulated seawater were investigated by means of potentiodynamic polarization curves, electrochemical impedance spectroscopy (EIS) and Mott-Schottky curves measurements. Microstructures of samples at different aging temperature were observed, and the phases presented in the heat-treated SDSS samples were also characterized by X-ray diffraction (XRD). In addition, the corrosion morphology after polarization was observed by optical microscope $(\mathrm{OM})$. The results showed that the $\sigma$ phase was not precipitated at $650{ }^{\circ} \mathrm{C}$, while it was found in the temperature range from $750{ }^{\circ} \mathrm{C}$ to $850{ }^{\circ} \mathrm{C}$. Furthermore, the amount of $\sigma$ phase was the most when aging at $850^{\circ} \mathrm{C}$, and the passive film became uneven and less dense with increasing aging temperature. The corrosion resistance of S32750 SDSS declined with the aging temperature was mainly ascribed to that the precipitation of $\sigma$ phase reduced the stability and thickness of the passive film, and the corrosion reaction was accelerated.

Keywords: Aging Temperature, $\sigma$ Phase, S32750 Super Duplex Stainless Steel, Simulated Seawater

\section{FULL TEXT}

(C) 2019 The Authors. Published by ESG (www.electrochemsci.org). This article is an open access article distributed under the terms and conditions of the Creative Commons Attribution license (http://creativecommons.org/licenses/by/4.0/). 